\title{
Harvesting Impact and Rehabilitation in Tropical Rain Forests
}

\author{
Shigeo Kobayashi \\ (Forestry and Forest Products Research Institute, Tsukuba, 305, Japan)
}

\begin{abstract}
A bstract
Variations in forest structure, soil and microclimate were surveyed before and after harvesting. The logged-over forest degraded at the point of forest structure and soil condition. After that, natural regeneration can not be expected. However, microclimatic conditions at the open site which were created by selective cutting, were similar to a natural gap. Thus, "Forest Patch Improvement" and "Gap Planting" were proposed as rehabilitation methods for logged-over forests.

Key words: tropical rain forest, forest harvest, changes of forest ecosystem.
\end{abstract}

\section{Introduction}

A global population of 5.4 billion people is threatening the productive capacity and sustainability of the earth. The earth is covered with 4.5 billion ha of forests which are distributed $43 \%$ in the tropics (Raven,1991). Neverthless, the tropical forest is decreasing by 17.0 million ha per year and forest land is being converted into agriculture fields, pastures and plantations. Moreover, 4.4 million ha of tropical forests are harvested and become degraded forests (logged-over forest) every year without adequate control and subsequent silvicultural treatment.

Decrease and degradation of the tropical forests affect not only the production of timber, but also the local and global environment. Natural disasters such as flooding, erosion, landslides, and desertification are increased. More than $20 \%$ of the topsoil of the world's arable lands has been lost over the past 40 years. Desertification is progressing by 6.0 million ha per year. Moreover, a great loss of biological diversity threatens to limit the possibilities for sustainable development in the future. Decreasing and degraded tropical forests also affect global warming in the two ways which are accelerating the green house gas emission such as carbondioxide, methane and nitrousoxide, and a decrease the accumulation of carbondioxide through the photosynthesis of trees.

Neverthless, the effects of forest harvesting have not yet been clarified, especially in the tropical rain forest (Lamb,1990). Site productivity decreases after harvesting, however these effects vary with regard to tree species, time and method of felling, method of yarding and reforestation, local climate patterns, topography and soil characteristics (Stone,1983). It would appear that the success of natural regeneration by Dipterocarp species depends on the impact of harvesting. The application of rehabilitation methods must be initiated at forest harvesting. Among tropical rain forests, the mixed Dipterocarp forest in Brunei is mainly discussed here. The purpose of this study was, 1) to clarify changes in forest structure, 2) clarify changes of soil, 3) compare the microclimate between residual forest and the open site which was created by selective cutting compared with a natural gap in mixed Dipterocarp 
forest, 4) the development of the rehabilitation methods on logged-over forest. 2. Site description

The study site was situated about $45 \mathrm{~km}$ from Sungai Liang, in Brunei Darussalam at about $100 \mathrm{~m}$ above sea level. An experimental plot was set 1 ha from ridge to stream. Soil in this study site was classified into red-yellow podzolic soil which showed thin A0 and A horizons, and pipestone at a depth of $150 \mathrm{~cm}$. This site consisted of mixed Dipterocarp forest such as Dryobalanops aromatica, Dipterocarpus globosus, Shorea laxa, Shorea exlliptica, Dipterocarpus exalatus, Dipterocarpus geniculatus; Shorea macrophylla, Shorea parvifolia, and Upuna borneensis. Dryobalanops aromatica was the dominant species. A large amount of Dipterocarp seedlings were observed on the forest floor before harvesting.

\section{Methods}

1) Survey and harvest: (1) A first survey was carried out in June, July and August 1987 before harvesting. (2)Selective cutting was done for commercial purpose in October 1987. Timber yarding by bulldozer was carried out in November and December 1987. (3) A second survey was carried out in June and July 1988 after harvesting.

2)Forest structure: (1)All trees more than $20 \mathrm{~cm}$ of D.B.H. for non-Dipterocarp species and $10 \mathrm{~cm}$ of D.B.H. for Dipterocarp species were measured and numbered before and after harvesting.

3) Soil survey: (1) Topsoils were surveyed from 100 pits at the center of small section $(10 \mathrm{~m} \times 10 \mathrm{~m})$. (2)The thickness of $\mathrm{A} 0$ and $\mathrm{A}$ horizons, and hardness of topsoils were measured. Topsoils were sampled using a 400cc cylinder and analyzed for their physical properties. Topsoils were also sampled and analyzed for total carbon and nitrogen contents.

4) Microclimate: (1) Air and soil temperature, light intensity on the floor, and soil water tension were measured in the logged-over area and residual forest using a data logger.

\section{Results and Discussion}

\section{1) Changes in forest structure}

The density of standing trees decreased after harvesting, but size class distribution reveals a similar pattern. Large sizes of more than $60 \mathrm{~cm}$ in D.B.H. were felled and small sizes were either dead or removed. However, a serious problem was the residual standing trees more than $60 \%$ of which recieved damage (Fig.1). This value is similar to Whitmore's results (1984). The main cause of death in trees was felling and yarding by a bulldozer whose trail occupied $26 \%$ of the harvested area (Fig.2). The survivors of broken stems, however, are not expected to be used for timber or to display regrowth. Before harvesting, Dipterocarp seedlings were abundant, but many of them were destroyed after harvesting because of the bulldozer trail was constructed at the center of seedling distribution. After that, natural regeneration can not be expected.

2) Changes of forest soil

Tree felling and yarding affect soil changes directly and soil properties were 
changed according to climate condition indirectly following these forestry activities. Severe variations in soil were caused by the removal or the deposition of topsoil by a bulldozer, thickness of A horizon decreased accompanied by organic matter decomposition in topsoil. Soil hardness was comparatively high and an average of $14 \mathrm{~mm}$ was recorded prior to harvesting, and this increased to $16 \mathrm{~mm}$ after harvesting caused by compaction. This compaction affected soil porosity and coarse porosity decreased from $35.5 \%$ to $24.7 \%$. Bulk density also changed to increase from 1.068 to 1.228 . According to these changes, the hydraulic conductivity of topsoil decreased from an average of $56 \mathrm{cc} / \mathrm{min}$. to an average of $46 \mathrm{cc} / \mathrm{min}$. before and after harvesting. Organic matter in the soil had its decomposition rate accelerated and total carbon and nitrogen contents decreased. Carbon loss was estimated at about $19.1 \mathrm{C} / \mathrm{ton} / \mathrm{ha}$. However, carbon and nitrogen accumulate again in forest ecosystems following the process of forest recovery (Jordan,1985).

3) Change of microclimate compared with natural gap

Microclimate also changed at an open site which was created by selective cutting under residual forest. Open site recieved stronger sunlight for a longer time than under residual forest. However, the floor of residual forest recieved much more sunlight from side than that of natural forest which indicated less than $5 \%$ in relative light intensity. Air temperature indicated high fluctuation at the open site and soil temperature remained low under the residual forest. Soil water tension at the open site represented more mesic than the residual forest by rain fall interception and transevaporation of standing trees as well as a natural gap compared with a natural forest. Conditions of microclimate at the open site were similar to those of the natural gap at the mixed Dipterocarp forest.

4) Rehabilitation methods of logged-over forest

Seedlings under the forest are distributed patchy surrounding the mother tree. These seedlings are not able to recieve sufficient sunlight because upper trees prevent sunlight from penetrating to them on the forest floor. Therefore, in order to improve the light conditions for the seedlings, substories and understories of nomcommercial species are cleared. This treatment is called "Forest Patch Improvement". The size of a clearing depends on the area of seedling distribution. This should increase the survival and growth rates of the seedlings.

Tropical rain forest consist of a mosaic of patches at different stages of maturity from gaps, through stands of small saplings or poles, to mature high forests. The forest regenerates itself through the formation of the gap. "Gap planting" is applied where there are no seedlings of commercial species. Harvesting activities have a strong tendency to destroy the seedlings. In fact, the logged over forest which has no seedlings of valuable species, can be located easily. Gap planting involves the planting of seedlings in artificially created gaps (Ochiai, 1990). The gap created by hole clearing must be wide enough for seedlings to recieve sufficient sunlight and must be created on a suitable site for the seedlings to be planted. 


\section{Conclusion}

1) Changes of forest structure indicated a similar distribution pattern of the D.B.H. size class accompanied by a decrease in the density after harvesting. This resulted from the removal and death of trees when large trees were harvested and small trees were damaged. Residual Dipterocarp trees showed unsatisfactory quality and more than $60 \%$ of them recieved serious damage.

2) Soil was degraded after harvesting. The thickness of the topsoil decreased and its hardness increased. Hydraulic conductivity decreased apparently on the bulldozer trail because coarse porosity decreased and fine porosity increased. Both total carbon and nitrogen decreased.

3) Variations in temperature and light intensity increased at the open site which was created by selective cutting. However, the open site indicated a more mesic than residual forest floor. Conditions of microclimate at the opens site represented similar pattern in the natural gap.

4) The logged over forest degraded. Therefore, new rehabilitation methods were proposed as "Forest Patch Improvement" and "Gap Planting" based on the information of changed forest ecosystems after forest harvesting.

\section{References}

Jordan, C.F., 1985: Nutrient cycling in tropical ecosystems. John Wiley \& Sons, pp. 190.

Lamb, D., 1990: Exploiting the tropical rain forest. Man and The Biosphere Series, UNESCO, pp.259.

Ochiai, Y., 1990: Silvicultural study on Dipterocarp species in Negara Brunei

Darussalam. Forest Research Note in Brunei Darussalam, No.6, pp.61.

Raven, P.H., 1991: Global change and sustainability: what are the issues? Global Environmental Forum, The United Nations University, 17-27.

Stone, E.L. ed., 1984: Forest soils and treatment impacts. The University of Tennessee, pp.454.

Whitmore, T.C., 1984: Tropical rain forest of the Far East. Clarendon Press, pp.352.

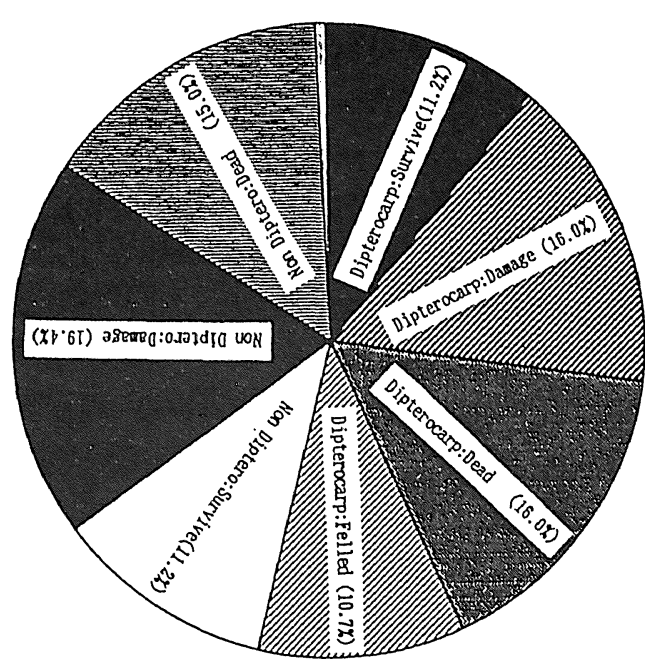

Fig.1 Harvesting impact on the mixed Dipterocarp forest structure. Trees measured more than $10 \mathrm{~cm}$ in D.B.H.. Total trees were counted 206 per hectare before harvest.

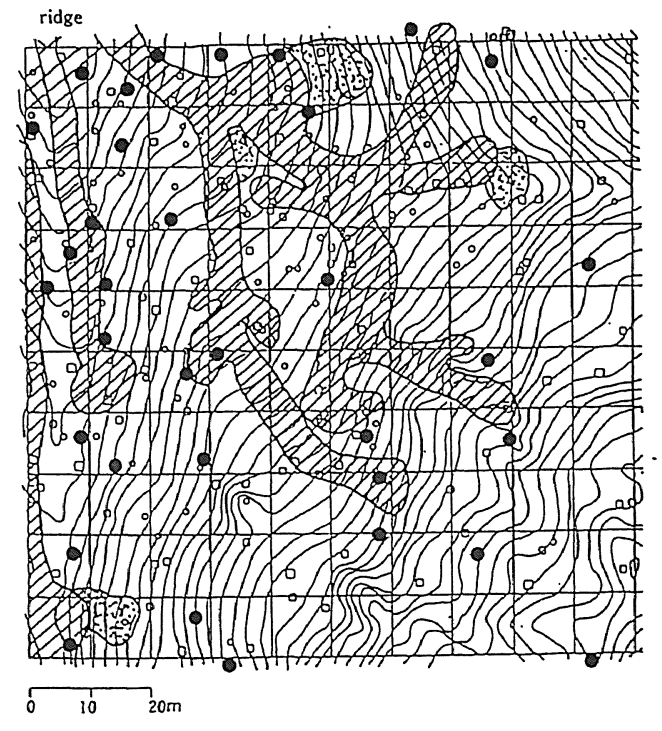

Fig.2 Tree standing position and bulldozer trail in mixed Dipterocarp forest at Labi Hills Forest Reserve. Dots (more than $58 \mathrm{~cm}$ in D.B.H.) and circles indicate Dipterocarp species and squares represent non-Dipterocarp. 